\title{
doispontos:
}

\section{Individuação psicossocial, coletivo e universalidade em Simondon ${ }^{1}$}

\author{
Paulo Vieira Neto \\ Professor, Universidade Federal do Paraná, Curitiba, Brasil \\ E-mail: vieiranetopaulinho@gmail.com
}

Resumo: Pela análise da individuação psicológica, como ela aparece na L'individuation à la lumière des notions de forme e d'information, de Gilbert Simondon, pretendemos estabelecer alguns princípios fundamentais de método, segundo os quais Simondon irá pensar o social, e depois o político. Pretendemos, com esses princípios, sublinhar a forma peculiar e original em que a filosofia de Simondon permite pensar a natureza do social e do político, sem reduzir as ciências do espírito às ciências da natureza ou vice e versa.

Palavras-chave: Simondon, individuação, psicossocial, método.

\section{Psychosocial individuation, collective and universality in Simondon}

\begin{abstract}
By the analysis of the psychological individuation, as it appears on L'individuation à la lumière des notions de forme e d'information of Gilbert Simondon, we shall bring some fundamental methodological principles to think the social and the solitical fields as does Simondon. With that principles in hand we will argue the originality and characteristical way that will be understood the political and the social fields, without any kind of reduction of the sciences of nature and the humanities one to another.
\end{abstract}

Key-words: Simondon, individuation, psychosocial, method.

I

O recurso à detecção dos fios transindividuais que compõem tanto as instituições sociais quanto as personalidades singulares caracteriza, de maneira peculiar, a estratégia segundo a qual Simondon esboça as consequências de sua teoria da individuação e da informação para a psicologia e a sociologia - e, por que não, para a política. Isso implica a prioridade de um ponto de vista que não parte do indivíduo, da sociedade ou até mesmo de uma dialética entre indivíduo e sociedade, mas de um lugar prévio a essas duas ordens, lugar no qual elas se constituem, e isso tanto no plano da psicologia quanto no social e no político propriamente. O sentido dessa prioridade desenvolveremos adiante. Mas é clara, desde logo, a peculiaridade dessa tática: de um lado não ceder ao privilégio do social ou do individual para explicar a individuação de um agente ou a formação dos coletivos, de outro, dissolver o isolamento e a polarização entre o universal e o individual tanto no plano da psicologia quanto no plano da sociologia (e da política). Tanto a ideia liberal de um indivíduo, entendido como um dado imediato, disputando posições com outros indivíduos em um meio universal construído quanto a de indivíduos, produzidos a partir de universais que lhes são prévios, desaparecem completamente em nome da estratégia de pensar a formação conjunta do 
individual e de seu meio. Ora, o peso e a verossimilhança dessa maneira astuciosa de pensar o coletivo e o individual, e então, de relacionar o caráter individual com os universais que podem definir o sentido das ações e instituições sociais e pessoais, estão concentrados no uso de conceitos como o de transindividual e afins, conceitos que não são imediatamente evidentes e devem, pelo menos preliminarmente, ser um tanto quanto esclarecidos.

O transindividual, já em seu termo, passa perto de evocar um paradoxo, se não uma contradição, porque parece reunir, na mesma esfera de compreensão de "individual", o indivíduo em sua distinção característica - digamos, em sua repulsão no que concerne a tudo aquilo que ele não é - e aquilo mesmo de que ele se distinguia como indivíduo na esfera de compreensão do prefixo "trans"2. Simondon contorna esse aparente paradoxo usando o termo para compreender aquilo que, em cada indivíduo envolvido em um regime de individuação determinado, permanece não individual. Antes que se objete que isso apenas faz passar de um paradoxo a outro, observe-se que Simondon entende a individuação, e por consequência a individualidade mesma, como algo sempre incompleto e mergulhado em uma virtualidade pré-individual, de tal maneira que sempre resta uma margem aberta de pré-individualidade a partir da qual é possível a instituição de um trânsito da relação real de um indivíduo à de outro, através de um meio. Em outros termos "toda individuação é relativa" (Simondon, 2005, p. 25).

Diríamos: toda individuação tem algo de inacabado, daí a possibilidade do transindividual. Ora, precisamente nesses espaços inacabados se flagram relações constitutivas que atravessam as individualidades respectivas. Isso esclarece o bastidor metafísico do ponto de vista simondoniano, frequentemente resumido, e com razão, na máxima: as relações instituem seus termos. Tal inacabamento ontológico é a presença resiliente e indelével de relações com um meio e com outras individuações na formação de uma multiplicidade. Isso determina um ponto de vista que, na verdade, parte da alternativa ontológica mais profunda, de acordo com a qual Simondon concede a precedência da relação que constitui o indivíduo frente ao indivíduo ele mesmo, que é termo da relação constituinte. Em suma, as relações constitutivas, as gêneses, precedem seus extremos e, em consequência disso, um fio transindividual pode ser detectado no tecido complexo das relações constitutivas de muitos indivíduos compartilhando a mesma ordem de grandeza e o mesmo meio, fios que atravessam os indivíduos, mas são prévios, e independentes da própria forma individual manifesta.

O custo disso, sublinhamos, é o de não assumir mais o indivíduo como dado, e passar todo esse peso para as atividades e as relações que o constituem. Se o indivíduo é resultado, algumas de suas relações com outros indivíduos pode ser legado de um momento não ainda individualizado. E se esse resultado nunca é consumado totalmente, o indivíduo em processo de individuação não consegue chegar até a exclusão recíproca de tudo o que está em seu relacionamento com a multiplicidade de indivíduos e virtualidades pré-individuais que são suas condições: o transindividual não é mais contraditório. Na verdade, ele passa a ser uma versão da compossibilidade lebniziana, em uma metafisica que não dá prioridade ontológica às substâncias (Cf. Simondon, 2005, p. 24).

Para o velho hábito de pensar a individuação como condição do dado (os dados são indivíduos à disposição para a construção de teorias) a solução de Simondon ainda pode parecer estranha. Passamos, para com contraiu esse hábito, do paradoxo ao estranhamento. Mas o segundo é o preço para vencer o primeiro, a estratégia de Simondon parece estranha porque descarta desde logo a tática de construir universais a partir de dados imediatos. O que isso tem de estranho, no entanto, parece ser compensado pelo ganho em compreensibilidade das relações entre um indivíduo e seu meio, seja na psicologia, seja na sociologia, seja na política (como sugerimos desde o começo). 
Vejamos a alternativa. Se partimos de indivíduos plenamente constituídos, primeiros ontologicamente - isso é, dados em ato - fica difícil explicar o que pode haver de comum entre eles, mas fica ainda mais difícil apontar alguma coisa que não seja afetada de alteridade quando se transita de um indivíduo a outro. Nesse caso a universalidade, aquilo que está presente em muitos indivíduos, só pode ser explicada por mecanismos como o de abstração, alguma forma de construção do comum por meio ou da intelecção, da linguagem, e assim por diante. Nessa alternativa o transindividual e o pré-individual são problemáticos. Mas a universalidade ela mesma corre o risco constante de ser uma forma vazia arbitrariamente construída pela linguagem ou pelo aparelho de conhecimento, no espaço realmente inexistente entre dois indivíduos ontologicamente incomunicáveis. Nesse quadro o caminho mais curto consiste em considerar toda relação como externa, partes extra partes. Logo, nesse quadro, o trans do transindividual tende a ser pensado como uma construção artificial entre indivíduos cuja repulsão metafísica garante um isolamento de princípio. Isso desenha a alternativa contra a qual Simondon está construindo sua tese.

Resta, no entanto, a alternativa de tomar o indivíduo como resultado posterior de uma gênese (e agora essa gênese, entendida como atividade e relação, é o dado). A saber, nessa alternativa, aceitamos que a realidade se constitui em uma gênese cujo núcleo apresenta-se como feixe de relações instituintes de seus termos, que tal relação constituinte é anterior ontologicamente à substância constituída, anterior nesse sentido preciso segundo o qual a substância pressupõe a relação e a atividade. Tais relações genéticas situam os indivíduos em circunstâncias determinadas segundo uma multiplicidade de vínculos que são antecedentes, e não, como na alternativa anterior, consequentes da história de uma individuação.

$\mathrm{Na}$ alternativa proposta por Simondon o transindividual, ocupa a função dos velhos universais, mas diferentemente deles, o faz registrando explicitamente seu papel constituinte e explicitando o processo pelo qual foi produzido. Resolver a aparência de contradição que ronda o termo transindividual, então, consiste em precisar, por ajuste fino, qual a diferença entre o ambiente metafísico que se pretendia estabelecer entre os universais e os indivíduos quando considerados como singulares. A metafísica proposta por Simondon permite ao transindividual, concretamente, transitar entre indivíduos. Concretamente quer dizer várias coisas aqui. Primeiro: estar em estado de relação sem romper completamente a membrana metafísica que separa um indivíduo, termo da relação, de outros de mesma ordem. Segundo: pensar o indivíduo sem separá-lo de seu meio ou, que é mais dramático, sem dissolvê-lo novamente em um meio mais amplo. Terceiro: aceitar que o imediato metafísico é na verdade um jogo de relações e atividades, um devir, e não um conjunto estático de dados. Que características o transdividual herda do velho universal? O transindividual passa de um indivíduo a outro, mas permanecendo o mesmo, realmente, em cada indivíduo envolvido na relação. Universal real.

Aqui uma precisão terminológica: o conceito de transindividual e de pré-individual não são coextensos nem se sobrepõe completamente em compreensão. Ao contrário, o pré-individual consiste no campo de forças a partir do qual constituem e reconstituem-se as fronteiras relativas de cada individualidade efetivada; o transindividual naquilo que, no interior do campo pré-individual transita entre os indivíduos e se estende como relação constituinte comum. Seu vínculo com o pré-individual é de tal ordem que se, como o universal, o transindividual se diz de muitos, ele não o faz por reflexão, comparação e depois abstração dos muitos indivíduos do qual se diz. Não se trata de colecionar indivíduos, mas, de detectar seu parentesco a partir de uma gênese comum. O pré-individual é uma camada virtual que está na base de todo indivíduo, e ainda não é um indivíduo; o transindividual é uma ligação também virtual, que acontece nessa camada virtual ela mesma, mas já o faz postas as individuações que entram em jogo em processos determinados de gênese.

Por certo, tanto o conceito de pré-individual quanto o de transindividual são um tanto quanto astuciosos. Substituem o velho universal abstrato, é claro, onde isso é necessário (e nem sempre é necessário). 
Astuciosos mas não paradoxais. Sua perspicácia está toda em exigir uma outra metafísica no lugar daquela que sustentava a concepção de universalidade abstrata. A estratégia é visivelmente contrária a algumas correntes da epistemologia herdadas da passagem do século XIX ao XX, sobretudo o empirismo lógico, e toca nos pontos cruciais para uma outra concepção das técnicas, das ciências e da própria filosofia. Mas não é ainda o caso de recuar até essa perspectiva mais ampla. O que nos interessa mais de perto é que essa manobra conceitual abre, de imediato, para pensarmos alguns problemas vinculados à individuação psicológica e social, o que desenvolveremos adiante.

O recurso à noção de transindividual recupera o caráter concreto da universalidade suposta nos processos de individuação sem dissolver o indivíduo em seu meio e sem sublimar o meio em um espaço arbitrário entre singularidades incomunicantes. Que o indivíduo e o meio se comunicam por processos reais e recíprocos é algo visível desde a individuação física até a individuação psicossocial, mas é na individuação psicossocial que essa característica se torna crucial. Isso deve ser entendido em três momentos fundamentais, o da psicologia, o coletivo, e por fim, já apontando para o campo das significações, no social. Vejamos o primeiro.

A psicologia de Simondon procura a individuação na convergência de pelo menos três linhas de força psíquicas: na ação - reação diante de um problema externo, na afetividade como equilíbrio-desequilíbrio psíquico em relação à alteridade, e na percepção como apresentação ou apreensão-constituição de um objeto. Nenhum dos processos de individuação em separado dá conta da individuação psicológica. Cada um deles começa como incompatibilidade em um meio que gera um campo de potenciais ${ }^{3}$. A percepção, por exemplo, culmina com a invenção de uma forma - o que implica a alteração do sujeito da percepção e do objeto percebido (ou do campo de sensações em que se constrói a percepção) em algum sentido. Assim, uma criança pode perceber a forma do corpo de um animal a partir da forma em que percebe seu próprio corpo, sem o recurso a esquemas geométricos: a tensão de uma determinada situação coloca em jogo o esquema corporal daquele que percebe como do que é percebido, partindo de uma situação original de crise e de metaestabilidade, para a formação da figura estável do animal como objeto de percepção. Mas, mesmo nesse caso, afetividade, ação física e sensação confluem para o estabelecimento da solução do problema posto em reconhecer as formas do corpo de um animal (Simondon, 2005, p. 236).

Na verdade, o mais das vezes, a percepção apresenta uma sistematização do mundo mais que um objeto (Simondon, 2005, p. 244). Isso porque, já no momento da percepção, opera uma tensão entre a quantidade de informação necessária para formar o todo da percepção e a inércia das formas em que essa informação se coagula. Vejamos o exemplo que Simondon oferece coma película fotográfica. São as características físico-químicas da película que permitem calibrar o quanto de partículas de prata se precipitam dado um tempo de exposição da película à luz. O maior número de partículas permite a expressão de informações mais precisas sobre a característica da luz que impressiona o papel: quanto maior o número de partículas precipitadas, mais informação e mais diferenças contidas na luz a que a película foi exposta são agregadas ao papel fotográfico impressionado. No entanto, o contraste da foto se origina não da simples precipitação de partículas no papel fotográfico, mas disso em relação com as circunstâncias que limitam a informação aglutinada pela precipitação das partículas (iluminação do objeto fotografado, ângulo da exposição, variedade da coloração original e dos reflexos contidos no objeto fotografado, tempo de exposição e assim por diante $)^{4}$. Perceber, enfim, consiste em uma atividade na qual os sujeitos da percepção interagem e se alteram formando um mundo, resolvendo um problema de estabilidade do conjunto de sensações - por uma forma particular de reduzir a tensão entre forma e informação em um caso dado. 
A afetividade, certamente não está excluída do processo anterior, embora o vocabulário das questões que a envolvem - diga-se de passagem um dos temas recorrentes da filosofia clássica desde antes de Descartes ou de Cicero - seja um tanto deslocado, se trata também de estabilizar a tensão entre forma e informação, resolvendo uma relação com o mundo. A afetividade acontece dentro do sistema perceber-agir-integrar, mas de uma maneira que lhe é própria. Segundo Simondon, a afetividade aparece na coincidência entre causalidade e finalidade de tal forma que julgar e agir estão sobrepostos (Simondon, 2005, p. 247).

Nesse momento a tese sugere uma ruptura importante com a psicanálise. Enquanto na última se postula um inconsciente como um "psiquismo completo" na primeira o inconsciente é "a capacidade de ação do sujeito" (Idem). É que toda ação disfarça seus bastidores e o sujeito se engana mais frequentemente "sobre aquilo que quer e que não quer" (Idem). Assim entre o subterrâneo da ação e o céu estrelado da percepção se estende a emotividade como "subconsciência", no limite da consciência e da inconsciência, entre o contínuo da consciência e o descontínuo da ação. O centro da individuação psíquica é a afetividade entendida como liminar entre ação e representação.

É desse centro que irradiam os universais da comunidade: a proximidade dos afetos sendo um elo de união. Mais radicalmente, é pela afetividade que são possibilitadas a comunicação e a expressão intersubjetivas: "nem a comunidade de ação, nem a identidade dos conteúdos de consciência são suficientes para estabelecer a comunicação intersubjetiva" (Simondon, 2005, 249). Essa característica da afetividade, que a torna empática e compartilhável, faz com que Simondon funde sobre ela o que ele chamará de comunicação simbólica. Fica irresistível, nesse caso, a citação de Espinosa segundo a qual "sentimus experimmurque nos aeternos esse", sentimento de eternidade que Simondon explora na chave da permanência do que há de simbólico no afetivo. O vínculo histórico do indivíduo com o passado e o seu posicionamento efetivo no presente, ambos, são postos no plano da afetividade como espaço simbólico. A Espiritualidade, que surge no campo do afetivo, consiste em permanência do pré-individual no individual retomado pelo respeito (afetivo). Vale apresentar em seus próprios termos a conclusão de Simondon sobre o valor da afetividade (ou da afetividade como instauração do valor): "A afetivo-emotividade é um movimento entre o indeterminado natural e o hic et nunc da existência em ato, ela é aquilo pelo que se opera, no sujeito, a tomada do indeterminado em direção ao presente que vai incorporá-lo no coletivo" (Simondon, 2005, p. 252).

Tudo isso porque a afetividade é fundamento da emotividade assim como a percepção é fundamento da ação. As duas são gênese de subjetividade. Parece, nesse momento do texto da tese, que encontramos o salto que o problema da individuação dá da individuação biológica ã psicossocial. É a significação da ação e da emotividade que gera o espaço onde se desenvolvem os novos regimes de individuação que superam o biológico e o físico - e que de uma forma importante deverão desenhar o horizonte da individuação técnica.

A verdadeira convergência que descreve a gênese do indivíduo psicossocial, portanto, é a seguinte: a série percepção-ação se aproxima da série afetividade-emoção no seio de uma coletividade nascente (das relações reais entre o que está se individuando e outras individuações de seu meio). O coletivo, portanto, é o lado reverso da afetividade e da emotividade e está vinculado a elas como vale de uma montanha. Entenda-se que a subjetividade nascente não se perde no coletivo, não se confunde com ele, mas também não faria sentido sem ele. Igualmente o coletivo não pode ser reduzido à causa da subjetividade nascente se não quando encaixamos essa causalidade no quadro mais amplo da gênese da percepção e da emotividade desenhando uma subjetividade. O cogito ficaria assim: penso, sinto, logo existimos. Por sua vez, os dois movimentos de posição da subjetividade, tanto a ação quanto a emoção, são a polaridade própria daquilo que Simondon chama de espiritual: a ação sai do sujeito e se objetiva em eternidade, a emoção reflui sobre o sujeito e o vincula ao instante. 
Ora, compreender o que significa a espiritualidade é algo muito significativo quando se lê Simondon como uma modulação do materialismo. Na verdade, o texto da tese vai mais longe a aponta ciência e fé como extremos expulsos da espiritualidade e a espiritualidade como condição de permanência na intersubjetividade (Simondon, 2005, p. 254). Além disso a crítica que Simondon faz ao humanismo também encontra seu ponto de apoio aqui. Trata-se de manter uma compreensão do humano a partir da espiritualidade, que não se realiza nem no homem objeto de ciência nem no homem teatro da fé.

Certamente ainda há muito o que dizer sobre a psicologia de Simondon, sobretudo se a colocamos lado a lado com as psicologias da forma, com o associacionismo e com as psicologias típicas dos anos 50. No entanto é a construção do conceito de espiritualidade, como um fio que une o sujeito em formação com o coletivo, que leva ao ponto no qual o psíquico passa ao social e vice-versa. Entendido isso é preciso dar conta do problema posto pela individuação de uma subjetividade nascente. Isso se concentra no conceito de angústia, mobilizado por Simondon como elo entre o sujeito por se fazer e o sentido coletivo que ele pretende carregar. Isso porque a subjetividade nascente é o baixo relevo da sociabilidade nascente.

Entenda-se que a subjetividade é uma construção quase técnica - só não o é completamente por não ser produção de um objeto externo ${ }^{5}$. O sujeito é resultado da construção de uma história dotada de significado. Isso o coloca do lado da ação que se consuma nos objetos históricos, coletivos, e do lado do instante próprio dos valores emotivos. Todavia, a posição do sujeito par si mesmo, como problema, se faz na angústia (Simondon, 2005, p. 253). A descrição que Simondon faz da angústia é suficientemente viva e explícita para ser apresentada como argumento:

O presente se fecha perdendo sua atualidade, o mergulho no passado e no futuro dissipa a trama do presente e lhe toma sua densidade de coisa vivida. O ser individual se vai, desertando de si mesmo. E, no entanto, nessa deserção, há subjacente um instinto de se lançar à recomposição adiante, em outro lugar e de outra maneira, ao reincorporar o mundo de tal forma que tudo possa ser vivido. $\mathrm{O}$ ser angustiado se dissolve em universo para encontrar uma subjetividade outra: ele se transforma com o universo, afundando nas dimensões do universo (Simondon, 2005, p. 256).

A angústia simondoniana desfaz o percurso de individuação que vimos anteriormente, porque essa prova da subjetividade não se resolve no coletivo: ele faz a subjetividade caminhar de volta ao pré-individual. Angústia acompanhada de solidão constitutiva que Simondon coloca como condição de uma nova individuação.

\section{III}

Voltemos à afetividade e à sensação. Elas abriam um espaço, com uma métrica e uma orientação, com graus de liberdade determinados. A afetividade se dissipando em dois sentidos, o prazer e a felicidade de um lado, e a dor e a tristeza de outro. Felicidade e tristeza elas próprias constituindo uma direção mais que afetos particulares (Simondon, 2005, p. 257). A sensação, vinculada ao tropismo, reconhece também dois sentidos (calor-frio, luz-escuridão, leve-pesado, etc.) e se abre em diferentes direções e pontos de fuga, de linhas de orientação de natureza diversa - a que liga o escuro ao claro, o frio ao quente, o pesado ao leve e dirige a ação do tropismo. Mas para que esses espaços se tornem mundos é preciso a gênese de uma subjetividade. Por certo a orientação que consiste na essência da percepção (perceber é selecionar direções) e a orientação que consiste na essência da emotividade (a emotividade é a construção de uma felicidade ou de uma tristeza) são rebatidas sobre esse mundo da subjetividade como meridianos e paralelos.

Aqui cabe uma pequena digressão: nesse exato ponto podemos encontrar o elo entre a individuação do vivente e a individuação psicossocial. É o vivente que se coloca entre o quente e o frio, entre o claro e o 
escuro, etc. (Simondon, 2005, p. 259). É a condição própria do vivente que determina o lugar ótimo como ponto de origem na direção das sensações e a fratura em dois sentidos. Daí a importância da polaridade dos tropismos para o argumento de Simondon, daí também a insistência, na tese, em relacionar a sensação com o tropismo. A mesma coisa vale para a afetividade o ponto de virada entre o prazer e a dor remete à condição do ser vivente.

Todavia a afetividade coloca alguns problemas a mais, diante da sensação. A diferença entre a primeira e a segunda, é que a afetividade tem seu centro na subjetividade se individuando, e seus modos são independentes do espaço aberto pelas sensações. De fato, o quadro aberto pela afetividade é mais da natureza do tempo que do espaço - é mais um calendário que um mapa. A afetividade organiza o devir. Não um devir mas devires tão díspares quanto as diferentes direções qualitativas (do frio ao calor, do escuro ao claro) abertas pela sensação. Então: a afetividade abre diferentes temporalidades. A emoção é uma integral desses diferenciais (aquilo que Espinosa chamava de conatus) assim como a percepção é a integração dos gradientes de sensação ao longo de todas suas diferentes dimensões. Para seguirmos de perto o método somondoniano de investigação temos de explicitar claramente o que é problema, e o que é solução. As sensações e a afetividade são problemas cuja solução é a percepção e a emoção, respectivamente. O passo seguinte do método consiste em reconhecer o salto ontológico do problema à solução. Emoção e percepção são de outra ordem que sensação e afetividade. A emoção, em particular, é um cristal de tempo, retirado das temporalidades próprias ao afetivo, e integrado por uma subjetividade:

[...] a emoção se caracteriza pelo fato de ser como uma unidade temporal insular, tendo sua estrutura, ela conduz o vivente, lhe dá um sentido, o polariza, assume sua afetividade e a unifica. A emoção se desenvolve enquanto a afetividade é somente sentida como pertinência do estado atual a uma das modalidades do vivente (Simondon, 2005, p. 256).

Se a sensação e a afetividade encostam na condição do vivente, suas integrações saltam em direção a uma subjetividade. É por isso que não podemos reduzir os princípios das individuações psicossociais aos da individuação do vivente. Isso quer dizer que a variedade e a riqueza do psicossocial não é nem um epifenômeno de causas biológicas nem o resultado de uma atuação espiritual transcendente.

Emoção e percepção são a primeira integração do afetivo e da sensação. Mas elas abrem um novo problema, agora centrado na subjetividade se individuando através delas. É que a emoção determina uma atitude subjetiva e a percepção um ponto de vista objetivo. As duas coisas, de alguma maneira desorganizam a integridade do sujeito nascente e, por isso, implicam uma nova integração:

[...] é necessário que as emoções se encaminhem aos pontos de vista perceptivos e os pontos de vista perceptivos às emoções. Uma mediação entre percepções e emoções é condicionada pelo domínio do coletivo, ou o transindividual. O coletivo para um ser individuado é o lugar misto e estável no qual as emoções são pontos de vista perceptivos e os pontos de vista emoções possíveis. A unidade da modificação do vivente e da modificação do mundo se encontra no coletivo (Simondon, 2005, p. 261).

Essas integrações sucessivas têm um sentido geométrico. A afetividade e a sensação formam linhas, sua integração - exigida pela multiplicidade conflituosa de temporalidades e direções para os tropismos, respectivamente - gera áreas: a emoção e a percepção como atitude e ponto de vista, respectivamente. A multiplicidade de atitudes e pontos de vista, que diluem a coesão da vivência de uma subjetividade, pede uma segunda integração que agora se resolve em um volume: o espaço da coletividade, o vínculo entre alteridades, uma nova ordem de grandeza (a linha se mede em metros, a área em metros quadrados, o volume em metros cúbicos, mas de uma medida a outra há um salto na natureza das grandezas). Além da natureza diferente do coletivo, uma nova ordem de grandezas se constitui naquela das coletividades e do social. 
O leitor da tese deve prestar atenção em um passo importante que acontece ao longo dessas integrações próprias à individuação psicossocial. Da sensação e da afetividade até a posição de um mundo onde há individuações em relação, formando uma coletividade complexa, o que se desenhou foi uma solução particular do velho problema dos universais. Problema que pode ser formulado, para fins de nosso argumento, nos seguintes termos: como é possível que uma mesma coisa possa ser compartilhada por vários indivíduos diferentes, se estes indivíduos forem também singulares. Ao mesmo tempo, se pudermos chamar de objetividade aquilo que pôde ser compartilhado por uma complexidade de indivíduos capazes de percepção e afetividade, constituiu-se uma forma particular de conceber a gênese da objetividade, em paralelo com a explicação da gênese de subjetividades que se ligam num coletivo.

Esse é o segredo que permite a Simondon saltar da consideração da ligação entre a individuação psíquica e a social para o problema da significação. Assim, a tese vai definir o sinal como a relação real entre indivíduos em formação em um complexo psicossocial. Em cada indivíduo complexo esse sinal poderá ser uma significação, cumprida uma cláusula importante: há significação na exata medida em que há individuação (Simondon, 2005, p. 262). A significação é uma solução (uma entre várias possíveis) de alguma incompatibilidade entre sinais. Daí a posição de um princípio geral que irá orientar metodologicamente toda investigação simondoniana de processo de individuação em geral:

\begin{abstract}
[...] o indivíduo é autoconstituição de uma topologia de ser que resolve uma incompatibilidade anterior pela aparição de uma nova sistemática. Aquilo que era tensão e incompatibilidade se torna estrutura em funcionamento, a tensão fixa e infecunda se torna organização de funcionamento, a instabilidade se comuta em metaestabilidade organizada, perpetuada, estabilizada em seu poder de mudança. O indivíduo é assim uma axiomática espaço-temporal do ser que compatibiliza os dados antes antagônicos em um sistema de dimensões espaciais e temporais (Simondon, 2005, p. 262, grifos do autor).
\end{abstract}

O que nos importa, sobremaneira, é sublinhar o momento em que Simondon explica o indivíduo como uma nova solução para uma incompatibilidade dada. Todo indivíduo é uma criação nesse sentido - se nos for permitido usar esse termo e, ao mesmo tempo, afastarmo-nos de seu sentido teológico como criação a partir do nada. Ao mesmo tempo, cada indivíduo porta uma referência à alteridade, ao coletivo de soluções ao qual sua solução pode se aliar.

A significação porta em si os dois momentos da individuação, o da novidade e o da coletividade, e é por isso que as significações podem ser partilhadas. A individuação psicológica, no final das contas, passa a ser instituição de significações e por isso ela pode ser menos que psicossocial - essa dualidade a faz diferente das individuações biológica, física e técnica ${ }^{6}$. Abre-se na individuação psicossocial um interior no lugar da afetividade e um exterior no lugar da sensação, mas também se abre uma medida comum entre os exteriores e os interiores numa coletividade. Institui-se a comunicabilidade e a possibilidade de compartilhar significações.

Isso quer dizer, antes de mais nada, que, do ponto de vista simondoniano, o projeto de uma teoria do conhecimento não pode se cumprir fora da continuidade entre o plano da individuação biológica de fundo (que podemos chamar de Natureza) nem do plano coletivo em que se resolvem as tensões da individuação psicológica (o que podemos chamar de cultura). Nem uma epistemologia naturalizada nem uma epistemologia sublimada na ideia de atividade de um espírito ou reduzida a sua dimensão social. A teoria do conhecimento simondoniana se desenha entre Natureza e Cultura. Ao mesmo tempo, a teoria do conhecimento não poderia ser explicitada, sem que se contasse a longa história dos regimes de individuação. 
Não se trata de dizer que a história das individuações culmina com uma teoria das significações e uma consequente teoria do conhecimento. Assim como um regime de individuação não subsume outro (e uma ciência a ele associada não se reduz a outra), o regime psicossocial não tem a propriedade específica de subsumir todos. Mas é a complexidade do que está em jogo, na ideia de um saber que alcança o mundo em sua efetividade, que exige que essa longa história seja contada para que, nas suas entrelinhas, possamos detectar o que seria uma legítima teoria do conhecimento.

A parte isso, um segundo ponto importante no percurso que examinamos até aqui se encontra no apagamento de uma passagem nítida das ciências da natureza às do espírito - na verdade, esse vocabulário ele mesmo perde sentido. As categorias de umas e de outras se permitem misturas, controladas por certo. Os saltos de natureza e de ordens de grandeza são na verdade o que organiza o bom uso de categorias e de universais de um regime de individuação a outro.

Ora, sem a estratégia que reapresenta o problema da significação sob essa roupagem nova, situando na gênese do indivíduo psicossocial o lugar da partilha de significações, essa costura delicada de universais seria desfigurada em alguma forma de nominalismo ou de realismo caricaturais. Uma primeira importante consequência da maneira como Simondon caracteriza a gênese psicossocial é essa instituição de uma teoria das significações com todas essas características peculiares. Mas há uma segunda consequência.

$\mathbf{V}$

O texto da tese encaminha ao leitor uma série de questões políticas (ou pré-políticas, se o leitor ou a leitora preferir). Em primeiro lugar, a tese de uma sociedade constituída de indivíduos independentes cuja comunidade se define a partir de sua repulsão ou atração recíprocas não poderá ser encarada se não como uma abstração excessivamente empobrecedora da complexidade do psicossocial. Da mesma forma, a tese da constituição das individualidades no interior de uma sociabilidade como ambiente universal simplifica a mesma complexidade. O psíquico e o social são o alto e o baixo relevos de um mesmo processo complexo de gênese, e sua relação não é a de antecedente e consequente, mas a de expressões coetâneas de um mesmo processo. Há individualidade, mas não há individualidade completa, há universalidade, mas não há universalidade transcendente à gênese dos indivíduos.

Assim, o problema das incompatibilidades no jogo de diferenças próprias ao social está vinculado às possibilidades abertas pelo compartilhamento de significações. Isso implica que a relação interindividual não se sobreponha completamente a uma relação interpessoal:

É muito insuficiente fazer apelo a uma comunicação de consciências para definir a relação interpessoal. Uma relação interpessoal é uma mediação comum entre a individuação e a individualização de um ser e as de um outro. Para que esta única mediação seja possível para duas individuações e duas individualizações deve haver comunidade separada de individuações e individualizações [...] a comunidade não pode intervir antes da constituição das personalidades, é necessário que uma comunidade anterior das condições da personalidade permita a formação de uma única mediação (Simondon, 2005, p. 265).

A relação interpessoal - cuja integração são as relações políticas - segue uma lógica paralela à relação entre um indivíduo e um meio. A alteridade questiona a individuação, e podemos esperar, nisso, o surgimento de potenciais e tensões, de uma série de problemas que terão, ao fim e ao cabo, significações políticas, também.

Isso já fica implícito no exemplo mesmo de que se serve Simondon: 
Perceber uma mulher como mulher não é fazer entrar uma percepção nos caminhos conceituais já estabelecidos, mas, situar a si mesmo enquanto individuação e individualização em relação a ela. Essa relação interpessoal comporta uma relação possível de nossa existência como ser individuado com relação à dela (Simondon, 2005, p. 266).

Solução possível da diferença entre existências. Essa maneira sofisticada de pensar uma significação de diferença de gênero remete implicitamente ao conceito de reconhecimento, mas mantém a multiplicidade de possibilidades do reconhecimento e mantém a tensão recíproca entre os que se reconhecem. Reconhecer altera as subjetividades em jogo, e não é, em absoluto, um ato que condiciona, mas um ato que se desprende de duas existências dadas. As subjetividades não são nunca absolutamente constituintes ou constituídas. É por força disso que sempre está presente a possibilidade de múltiplas soluções diferentes e novas para velhas questões (podemos conceder que, em cada caso novo há uma alteração da questão original, mas, seria tranquilo para Simondon, apontar um método nessas variações).

Talvez seja preciso organizar um pouco os conceitos mobilizados para dar conta do que implicitamente chamamos de reconhecimento, ultrapassando um pouco o vocabulário de Simondon. Vimos até aqui o que é individuação, o devir que separa uma porção de um meio através de um salto nas ordens de grandeza. Está tacitamente pressuposta a diferença entre individuação e individualização. A individualização é uma integração de ordem superior à da individuação, é uma individuação no interior de um processo prévio de individuação. Essa segunda individuação gera, no quadro do vivente individuado psicologicamente, a sexualidade (com ela os gêneros) e, além disso, as relações sociais. O indivíduo vivente dotado de um aparelho psicofisiológico se individualiza e então institui novas significações que, por sua vez, separam o psíquico do somático (Simondon, 2005, p. 268).

Antes de avançarmos cabe especificar um pouco mais esse movimento. Essa decantação do psíquico e do fisiológico (a individualização do vivente) projeta uma paridade entre o psíquico e o fisiológico: os órgãos do corpo são o correlato de funções psíquicas "realidades complementares" (Simondon, 2005, p. 268) que exprimem o indivíduo vivo. Daí que possamos chamar de corpo "o conjunto de especializações do vivente às quais correspondem especializações psíquicas" (Idem). A individualização do vivente produz corpos e almas não completamente individuados. A personalidade é o estado "quântico" (Idem) dessa produção. Por quântico Simondon pretende dizer que a personalidade se manifesta por saltos e por reestruturações - um vivente vai tendo muitas personalidades ao longo de sua história, e, na verdade, sua história é justamente as rearticulações de personalidades. Cada salto de uma personalidade a outra envolve uma crise e uma reestruturação.

Se nos for permitido, nesse momento, um salto para fora do texto, as estruturas do que estamos chamando de reconhecimento se instituem entre as expressões de personalidade assim como entre os corpos e o psiquismo. A política resolve ou decanta as tensões de uma multidão de afetos, assim como organiza as relações entre uma multidão de corpos. Se encontramos na política o segredo da unidade de um corpo social formado por individualizações que se reconhecem e atuam umas sobre as outras então, para Simondon, ela opera uma integração entre as personalidades psicologicamente individualizadas. Essa integração irá aparecer como instituição de uma nova temporalidade, própria do social:

O indivíduo encontra na sociedade uma exigência definida de futuro e uma conservação do passado, o futuro de um indivíduo na sociedade é um futuro reticulado, condicionado pelos pontos de contato, e que possui uma estrutura muito análoga ao passado individual. $\mathrm{O}$ engajamento na sociedade, para o indivíduo, o dirige ao fato de ser isso ou aquilo ... o indivíduo se vê propondo fins, papéis a escolher ... a sociedade diante do ser individual apresenta uma rede de papeis através da qual a conduta individual deve passar (Simondon, 2005, p. 290). 
Administrar, gerenciar, mas também revolucionar, instituir, restituir, e a rigor todas as relações de poder que serão assunto da política são tributárias dessa temporalidade, fundada na própria unidade social. Deixemos essa história para depois. Frisemos, no entanto, percorridos todos os pressupostos para o começo da narrativa dessa história, os princípios que se impõe a partir das considerações sobre a individuação psicossocial, ou da pré-história do social já presente na individuação psicológica. São, ao todo, quatro princípios que determinam um método para o que será a sociologia e depois a política simondonianas.

Primeiro: não é possível separar completamente o ponto de vista psicológico do sociológico, porque, como vimos, o social já comparece pressuposto no psicológico dado o caráter que assume o coletivo na individuação psicológica. Não há uma antinomia entre a psicologia e a sociologia, a primeira tratando do indivíduo a segunda, do grupo.

Segundo: o poder não é uma operação transcendente sobre os agentes sociais, mas uma rede pela qual a ação dos indivíduos psíquicos individualizados se reconhecem e agem uns sobre os outros, se determinando reciprocamente. O poder não é substancial, mas, circunstância de uma complexidade de individualizações problemáticas.

Terceiro: o objeto da política não pode ser sublimado em agentes abstratos, mas deve ser reconhecido como corpos e psiquismos, como sentido e ação sobre corpos e almas e, no limite, sobre os viventes que se individualizam em corpos e aparelhos psíquicos.

Por fim, para parafrasear Espinosa, o ponto de vista social e político não pode ser entendido como um império dentro de um império, uma cultura saltando sobre uma natureza, mas deve ao contrário assumir a costura das duas coisas numa unidade de mistos - nem completamente naturais nem completamente sociais. Ou, voltando para o vocabulário simondoniano, os agentes políticos só são corretamente compreendidos como indivíduos individualizados projetados em relações nas quais se exprimem seus pontos de vista, suas afetividades elevadas ao estado de emoção e, a rigor, suas próprias existências. A política não é uma prática sublime...

\section{NOTAS}

1. Texto apresentado durante o COLÓQUIO INTERNACIONAL GILBERT SIMONDON: OS SENTIDOS DA INDIVIDUAÇÃO, realizado no Departamento de Filosofia da Universidade de São Paulo, de 05 a 07 de dezembro de 2018 (nota do editor).

2. Sobre o desenvolvimento do conceito ver Morfino, 2008.

3. Ver Simondon, 2005, p. 235, apresentando a fase anterior à percepção como incompatibilidade entre sujeito da percepção e meio.

4. Simondon, 2005, p. 240. Ao lado desse exemplo e para complementá-lo, Simondon pensa também a forma pela qual a tela de uma televisão constrói uma imagem com contraste.

5. Essa analogia entre individuação técnica e social se reflete no conceito de alienação técnica, Cf. Oliveira, 2015.

6. Sobre a individuação técnica em especial ver Lopes, 2015. 


\section{REFERÊNCIAS}

FEENBERG, A. "Simondon e o construtivismo: uma contribuição recursiva à teoria da concretização". In Scientia Studia, São Paulo, v. 13, n. 2, 2015, p. 263-81.

MORFINO, V. “Simondon e o Transindividual”. In Il Protagora, 2008. Disponível em: http://stoa.usp.br/ chrisdunker/files/1885/10582/Simondon\%20e\%20o\%20Transindividual\%20-\%20Victorio\%20Morfino. pdf. Acessado em: 02/02/2019.

LOPES, W. E. S, "Gilbert Simondon e uma filosofia biológica da técnica”. In Scientia Studia, São Paulo, v. 13, n. 2, 2015, p. 307-34.

OLIVEIRA, D. V. "A técnica como modo de existência em Gilbert Simondon: tecnicidade, alienação e cultura”. In Dois Pontos, vol. 12, n. 1, 2015.

SIMONDON, G. L'Individuation ã la lumiere des notions de form et d' information. Grenoble: Ed Millon, 2005. 